\title{
Genealogia foucaultiana e políticas educacionais: possibilidades analíticas
}

\author{
Viviane Klaus* \\ Morgana Domênica Hattge** \\ Kamila Lockmann ${ }^{* * *}$
}

\section{Resumo}

Este artigo aborda a importância da genealogia foucaultiana na análise de políticas educacionais. Para tal, foi dividido em quatro seçóes. Na primeira seção, argumenta-se que a genealogia foucaultiana, de forte inspiraçáo "nietzschiana", é uma forma de análise que se opóe à história como busca da "origem" (Ursprung), pois procura compreender os objetos de estudo a partir de sua trama histórica, buscando desnaturalizar tudo aquilo que é visto como se estivesse desde sempre aí, no mundo. Ao problematizar, descrever e analisar os ditos sobre políticas educacionais, a genealogia possibilita visibilizar os processos de constituição dessas políticas. Na segunda, terceira e quarta seçóes, são apresentadas três pesquisas nas quais a genealogia foucaultiana se constituiu como possibilidade analítica: a primeira tem como foco central As políticas educacionais, a emergência da administração da educação e seu deslocamento para a gestão educacional; a segunda pesquisa apresenta as condiçóes de proveniência e emergência do movimento Todos Pela Educação e anuncia a instituiçáo da performatividade como um de seus principais efeitos no cenário educacional brasileiro na atualidade; e a terceira pesquisa, ao analisar como as Políticas de Assistência Social, utilizando a educação escolarizada como lócus privilegiado de efetivação, operam sobre a população na atualidade e que implicaçôes tais políticas vêm produzindo na escola contemporânea, lança um olhar genealógico para a forma de constituição dessas políticas no presente.

Palavras-chave: Políticas Públicas em Educação. Foucault, Michel. História.

* Doutora em Educação pela Universidade Federal do Rio Grande do Sul (UFRGS). Professora do Curso de Pedagogia e do Programa de Pós-Graduação Mestrado Profissional em Gestão Educacional na Universidade do Vale do Rio dos Sinos (UNISINOS).

** Doutora em Educação Universidade do Vale do Rio dos Sinos (UNISINOS). Professora do Curso de Pedagogia do Centro Universitário Univates (UNIVATES).

*** Doutora em Educação pela Universidade Federal do Rio Grande do Sul (UFRGS). Professora do Instituto de Educação e do Programa de Pós-Graduação em Educação da Universidade Federal do Rio Grande (FURG). 


\section{Introdução}

No presente artigo abordamos a importância da genealogia foucaultiana na análise de políticas educacionais. Tal importância está relacionada com o entendimento da genealogia como um conjunto de procedimentos que nos possibilita tanto conhecer o passado quanto nos rebelarmos contra o presente (VEIGA-NETO, 2003). Este tipo de analítica se situa em uma vertente externalista que possibilita compreender a constituiçáo dos objetos estudados a partir de um conjunto de práticas sociais, culturais, econômicas e políticas.

Pode-se dizer que as políticas educacionais são produzidas no interior de práticas que não são lineares, progressivas, mas contingentes. Acreditamos que um olhar genealógico sobre as políticas educacionais permite compreender algumas das condiçóes que possibilitaram a sua constituiçáo, bem como compreender a sua produtividade, pois, ao mesmo tempo em que são produzidas, elas produzem muitos efeitos.

Em A genealogia da moral, Nietzsche (2004) diz que a história de uma coisa, de um uso, pode ser uma cadeia ininterrupta de signos, de novas interpretaçóes e ajustes, de forma que as causas náo precisam estar relacionadas entre si e podem suceder-se e substituir- se de maneira meramente casual. Interpretar os eventos, os documentos, significa figurar para eles uma inteligibilidade, dar-lhes uma forma, tramá-los, torná-los matéria para a construçáo de uma dada realidade do passado, datá-los de uma coerência (ALBUQUERQUE JÚNIOR, 2004).

Para melhor discorrer sobre o tema, organizamos este artigo em quatro seções. Na primeira seção, abordaremos a importância de estudos de inspiração genealógica na análise de políticas educacionais. A seguir, apresentaremos três exemplos, de três diferentes pesquisas que fizeram uso da genealogia em suas análises.

Importa dizer que as pesquisadoras estão vinculadas a grupos de pesquisa que articulam os estudos foucaultianos em seus três eixos - arqueologia, genealogia e ética (processos de subjetivaçáo) - com objetos investigativos na área educacional. No caso das investigaçóes realizadas por cada uma das autoras, a genealogia tem se mostrado uma importante postura metodológica, pois ela envolve todo um modo de pensar e compreender os processos educacionais mais amplos. "Como as coisas chegaram a ser como são?” é uma pergunta permanente em estudos de inspiração genealógica.

\section{A genealogia foucaultiana: um método?}

A primeira reflexão que se faz premente é a análise da pergunta que se apresenta como título desta seção: a genealogia foucaultiana pode ser considerada uma 
metodologia de pesquisa? Para responder a esse questionamento, apoiar-nos-emos em Veiga-Neto e Lopes (2010), quando analisam se há teoria e método em Michel Foucault. Os autores destacam:

[...] que náo é de qualquer maneira ou por qualquer caminho que se chega aos objetos. Ou, se quisermos: que, sem um método, não se chega a ter uma percepção ou um entendimento sobre as coisas. [...] Assim, um método é o caminho que podemos/devemos seguir se quisermos ir para algum lugar. No nosso caso, o método é o caminho a seguir para fazer uma abordagem, para chegar a algum entendimento sobre aquilo que se quer descrever, discutir, argumentar etc. (VEIGA-NETO; LOPES, 2010, p. 2).

A genealogia pode ser compreendida como um procedimento explicativo (MOREY, 1991) que analisa o saber em termos de estratégia de poder. Foucault não escreveu uma obra metodológica sobre a genealogia, porém existe uma série de princípios metodológicos para abordar a análise do poder que podem ser encontrados especialmente em Vigiar e Punir (1987). Na verdade, ao longo de toda a obra do autorarqueologia, genealogia, ética - encontramos alguns princípios metodológicos que se deslocam, se complementam e se reinventam.

Para Foucault, o método não é o caminho seguro como queriam Descartes e Ramus, até porque nada mais é seguro, previsível: nem os pontos de saída, nem o percurso, nem os pontos de chegada. E mais: não há um solo-base externo por onde caminhar, senão que, mais do que o caminho, é o próprio solo sobre o qual repousa esse caminho é que é construído durante o ato de caminhar. (VEIGA-NETO, 2009, p.88-89).

Portanto, a genealogia pode ser compreendida como uma maneira de ver e de entender as coisas. Ao problematizar, descrever e analisar os ditos sobre políticas educacionais - objeto de discussão do presente texto - ela possibilita visibilizar seus processos de constituição.

A genealogia foucaultiana, de forte inspiração "nietzscheana”, é uma forma de análise que se opóe à história como busca da "origem" (Ursprung), pois visa compreender os objetos de estudo a partir de sua trama histórica, procurando desnaturalizar tudo aquilo que passa a ser visto como se estivesse desde sempre aí, no mundo. Segundo Foucault (2002a, p. 17), "procurar uma tal origem é tentar reencontrar 'o que era imediatamente', o 'aquilo mesmo' de uma imagem exatamente adequada a si; [...] é querer tirar todas as máscaras para desvendar enfim uma identidade 
primeira". Para o autor, a pesquisa da origem se constitui um projeto metafísico que busca o momento e o lugar em que as coisas se encontrariam em um estado de perfeição. Sendo assim, Foucault recusa a pesquisa da origem e, no lugar de acreditar na metafísica, propóe que escutemos a história, seus acasos, suas agitaçôes, discórdias, surpresas, seus desvios e acidentes.

Estudando a obra de Nietzsche (2004, 2000, 2001), principalmente $A$ Genealogia da Moral, Humano Demasiado Humano e A Gaia Ciência, Foucault (2002a) localiza algumas palavras utilizadas pelo filósofo quando aquele se refere à genealogia, são elas: Ursprung (origem), Herkunft (proveniência) e Entestehung (emergência). No primeiro caso, como já vimos, encontramos "[...] uma entidade supra-histórica, qual um motor ou um sopro que coloca em movimento a história e que, assim, a precede a partir de um lugar metafísico qualquer" (VEIGA-NETO, 2003, p. 68). Dessa forma, Foucault, seguindo Nietzsche, recusa a pesquisa de Ursprung. Ele se propóe a desenvolver uma pesquisa orientada pelos dois termos precedentes - Herkunft e Entestehung - que marcam melhor a tarefa da pesquisa genealógica desenhada pelo filólogo alemão.

Herkunft, que pode ser traduzida por proveniência ou ascendência, significa um tipo de pesquisa que busca, na proliferação dos acontecimentos, as inumeráveis possibilidades de começo. Não acreditamos, aqui, em um ponto único entendido como a origem de tudo; em vez disso, buscamos, na dispersão dos acontecimentos, os diferentes começos possíveis. Trata-se de compreender que a constituição de um objeto é o resultado do entrecruzamento de uma variedade de práticas e discursos que tornaram possível sua existência em um dado momento histórico. Para Foucault (2002a, p. 21),

Seguir o filáo complexo da proveniência é [...] manter o que se passou na dispersão que lhe é própria: é demarcar os acidentes, os ínfimos desvios - ou ao contrário as inversóes completas - os erros, as falhas na apreciação, os maus cálculos que deram nascimento ao que existe e tem valor para nós; é descobrir que na raiz daquilo que nós conhecemos e daquilo que nós somos não existe a verdade e o ser, mas a exterioridade do acidente.

$\mathrm{Na}$ pesquisa de proveniência, é preciso analisar "a proliferação dos acontecimentos através dos quais (graças aos quais, contra os quais) eles se formaram" (FOUCAULT, 2002a, p. 20-21). A proveniência é entendida por Veiga-Neto (2003, p. 71) como "Uma investigação que não busca terrenos firmes, senão areias movediças, fragmentos, omissóes e incoerências que haviam sido deixados de fora pela história tradicional". Nas palavras de Foucault (2002a, p. 21) "A pesquisa da proveniência não 
funda, muito pelo contrário: ela agita o que se percebia imóvel, ela fragmenta o que se pensava unido; ela mostra a heterogeneidade do que se imaginava em conformidade consigo mesmo".

Já o terceiro termo empregado por Nietzsche e estudado por Foucault (2002a), Entestehung, pode ser traduzido por emergência, e designa o surgimento, o aparecimento de determinado objeto na história. Ele é pensado como "[...] o princípio e a lei singular de um aparecimento [...] é a entrada em cena das forças; é sua irrupção, o salto pelo qual elas passam dos bastidores para o teatro, cada uma com seu vigor e sua própria juventude" (FOUCAULT, 2002a, p. 23-24).

Enquanto a proveniência (Herkunft) busca os vários começos possíveis, inumeráveis, tentando marcar os acidentes, os percalços que contribuíram para a constituição de determinado objeto, a emergência (Entestehung) designa o momento em que, em um jogo complexo de forças, esse objeto vem à tona, surge, irrompe. Ela marca, portanto, o lugar de luta, de disputa entre as forças, que, tensionadas, produzem o aparecimento do objeto em estudo. Porém, é necessário certo cuidado com tal entendimento, uma vez que não se trata de buscar um ponto específico na história que determine exatamente o surgimento desse objeto, mas de compreender que o campo complexo de relaçóes, no qual ele se encontra inserido, produz um jogo de forças que cria as condiçóes de possibilidade para a emergência desse objeto: em um determinado tempo e em uma determinada sociedade. Desse modo, a emergência:

[...] é a entrada em cena das forças; é sua interrupção, o salto pelo qual elas passam dos bastidores para o teatro cada uma com seu vigor e sua própria juventude [...] Ninguém é portanto responsável por uma emergência; ninguém pode se autoglorificar por ela; ela sempre se produz no interstício" (FOUCAULT, 2002a, p. 24).

Sendo assim, a pesquisa genealógica parte do pressuposto de que as coisas, os discursos ou as verdades de uma época não têm origem, nem essência; sua constituição é marcada pela discórdia, pela dispersão, ou, como sugere o próprio Foucault (2002a), pelo disparate.

Além disso, como atenta Veiga-Neto (2003, p. 71-72), é necessário tomar cuidado "para que não se coloque, nesse passado, um conceito, uma ideia ou um entendimento que é do presente". Da mesma forma, é preciso ter cuidado para que não se coloquem, no presente, entendimentos ou conceitos de épocas passadas. Assim, ao olhar para a história como uma forma de compreender o presente, de compreender como as coisas se tornaram o que são, não estamos, em nossas pesquisas, buscando uma 
relação direta entre o que se fez e o que se faz em Educação nos dias de hoje. No lugar disso, pretendemos lançar um olhar genealógico para alguns recortes, algumas peças ou cenas do passado que podem ter contribuído para a constituiçáo de nosso presente.

Com esse intuito, nas próximas seçôes, apresentamos três pesquisas nas quais a genealogia foucaultiana se constituiu como importante postura metodológica na análise de políticas educacionais.

\section{As políticas educacionais, a emergência da administração da educação e seu deslocamento para a gestão educacional}

[...] Foucault náo está aí para nos dizer as verdades sobre as coisas, mas sim para nos ajudar a compreender de que maneiras, por quais caminhos, tudo aquilo que se considera verdade tornou-se um dia verdadeiro. Seu pensamento herdou de Nietzsche essa revolucionária noção de que a Filosofia deve ser, antes de tudo, uma atividade que nos leva a examinar as nossas relaçóes com a verdade [...]. (VEIGA-NETO, 2006, p. 87).

A pesquisa partiu das seguintes problematizaçôes: como a gestão educacional se tornou uma verdade? Que efeitos a gestão educacional - como verdade - produz? Como a gestáo se tornou uma questáo central nas discussóes educacionais? Como se deu a mudança de ênfase de uma concepção da administração educacional para a gestão educacional e o que essa mudança de ênfase implica?

Dessa forma, em vez de abordar a importância, as falhas, os modelos da gestão democrática da escola pública - questôes que também são extremamente relevantes na área educacional -, procuramos, nesta primeira investigação, compreender como a gestão educacional se tornou uma verdade, pois hoje é quase uma indecência duvidar da sua importância e da sua legitimidade. Podemos duvidar do seu funcionamento no interior das escolas, mas não da sua necessidade na construção de uma educação de qualidade. Importou, também, saber que efeitos a gestão educacional - como verdade produz. O que está em jogo não "é uma história do verdadeiro, não é uma história do falso: a história da veridição é que tem importância politicamente" (FOUCAULT, 2008, p. 50-51), pois ela procura compreender como aquilo que consideramos verdade se tornou um dia verdadeiro. Retomamos aqui o célebre dizer de Nietzsche (1996, p. 57): "inventamos as verdades. Esquecemos que inventamos. Esquecemos que esquecemos".

O estudo situou-se numa vertente externalista, ou seja, pertencem "à vertente externa as formulaçóes que procuram se situar pelo 'lado de fora' dos cânones daquela 
racionalidade iluminista, para tentar entender como viemos nos tornar o que somos, como viemos parar onde estamos" (VEIGA-NETO, 1995, p. 11-12). Em uma perspectiva nietzschiana, perguntar-se sobre o valor da vida, por exemplo, implicaria colocar-se fora dela (MARTON, 1999).

Portanto, o estudo da instituição escolar também se deu de forma externa. Para tornar essa questão mais clara, é possível recorrer a um exemplo dado por Foucault (2006) na entrevista Precisóes sobre o poder: respostas a certas críticas, realizada em fevereiro de 1978. Segundo Foucault (2006), já no seu primeiro livro, A história da loucura, suas análises não tiveram como centro o plano da instituição e da lei. Pelo contrário, o que ele procurou fazer foi mostrar como as instituiçóes psiquiátricas e toda a rede de poder contra a loucura, ou os loucos puderam se formar em um dado momento. Da mesma forma, "a loucura não existe como objeto a não ser dentro de e mediante uma prática, mas essa prática não é, ela própria, a loucura” (VEYNE, 1998, p. 264).

Igualmente, a gestão educacional também não existe como objeto. Ela é produzida no interior de práticas que não são lineares, progressivas, mas contingentes. Um olhar genealógico sobre a gestão educacional permite compreender algumas das condiçôes que possibilitaram a sua constituição. Permite, também, compreender a sua produtividade, pois, ao mesmo tempo em que a gestáo educacional é produzida, ela produz muitos efeitos.

Desse modo, esta pesquisa, a partir das lentes teórico-metodológicas dos Estudos Foucaultianos, procurou compreender como se deu a mudança de ênfase de uma concepção da administração educacional para a gestão educacional e o que tal mudança implica. O estudo partiu do contexto da década de 1990 - em que a centralidade da gestáo educacional é evidente - tendo como referência principal a Proposta "Educação e conhecimento: eixo da transformaçáo produtiva com equidade", que foi redigida no contexto dos anos 1990 pela Comissão Econômica para América Latina e Caribe (CEPAL) e pela Organização das Naçóes Unidas para a Educação, a Ciência e a Cultura (UNESCO), sendo considerada um documento fundamental no redimensionamento da organização escolar no contexto político, econômico e social contemporâneo, e o "Plano Decenal de Educação para Todos", do período 1993-2003, que foi produzido pelo Ministério da Educação Brasileiro (BRASIL, 1993b) a partir do acordo com a UNESCO. Os documentos apresentam as análises macro do contexto social, político e econômico, sendo que a noção de desenvolvimento é o fio condutor das propostas.

A partir desse primeiro movimento analítico, que consistiu no desenho de alguns contornos do contexto da década de 1990, a pesquisa traz um primeiro recuo 
histórico no sentido de compreender a constituição da CEPAL e da UNESCO e a sua inserção no contexto educacional brasileiro. Trata da importância da invenção do Terceiro Mundo e das decorrentes discussóes sobre desenvolvimento e subdesenvolvimento, bem como da necessidade de administração pública e de administração da educação nos contextos político, econômico e social do período pósSegunda Guerra Mundial. E é justamente aí que o segundo movimento analítico se constituiu possibilitando compreender que vários fragmentos do que foi dito, pensado e feito em termos de administração da educação após 1945 - emergência da administração da educação como um problema de ordem pública - tiveram sua proveniência na era Vargas (de 1930 a 1945). Pode-se dizer que a emergência da administração teve como principal condição de possibilidade a noção de desenvolvimento como uma invençấo que produziu toda uma possível concepção da realidade e ação dos países que se conhecem desde entâo como subdesenvolvidos (ESCOBAR, 2007). A administração, por sua vez, colocou em funcionamento um conjunto de práticas que foram utilizadas estrategicamente no governamento da população. Como o desenvolvimento não é natural, para que ele ocorresse, era preciso intervir, planejar, planificar, modernizar, ou seja, administrar.

O estudo mostrou como a administraçáo científica, tanto no âmbito da produção quanto no âmbito das relaçôes pessoais, tornou-se um modo de vida nos contextos econômico, político e social do pós-guerra. É importante ressaltar que este movimento analítico foi composto a partir de um amplo estudo bibliográfico: livros e artigos de Anísio Teixeira; materiais de estudiosos da Associação Nacional de Política e Administração da Educação (ANPAE); estudos sobre a invenção do Terceiro Mundo; escritos da CEPAL e da UNESCO; análises sobre o papel da CEPAL no contexto brasileiro. A partir deste estudo, foram selecionados os Cadernos de Administraçáo Escolar, publicados entre 1961 e 1982 (TEIXEIRA, 1964; RIBEIRO, 1965; BREJON, 1966; MASCARO, 1968; TEIXEIRA et al., 1968; DIAS, 1972; MELCHIOR, 1972; SANDER, 1982), pois materializam as discussōes realizadas pela ANPAE $^{1}$ desde a sua fundação e podem ser considerados como uma das primeiras tentativas de sistematização dos debates realizados sobre o tema nas décadas anteriores.

Com alguns fios da trama dispostos, foi possível investir no terceiro movimento analítico que consistiu em mapear outros rastros que pudessem fornecer elementos sobre a mudança de ênfase da administração educacional para a gestão educacional. Tal mudança de ênfase, apesar de suas (des)continuidades, conservava o mesmo fio condutor: a administraçáo e a gestão educacional que colocam em funcionamento um conjunto de práticas utilizadas estrategicamente no governamento da população. A partir deste movimento analítico é possível afirmar que: 
- As décadas de 1970 e 1980 foram um período de reestruturação econômica e de reajustamento político e social (HARVEY, 2001);

- A Teoria do Capital Humano, aliada a outras mudanças sociais, econômicas e políticas, provocará uma série de descontinuidades nas formas de governamento da população nas décadas de 1970, 1980 e, especialmente, 1990. Os questionamentos sobre as relaçóes entre Capital e Trabalho, sobre o valor econômico da educação e os segredos econômicos da qualidade da população causaram algumas rachaduras nas formas de administração da população, tal como se constituíram no período do pós-guerra;

- Nos dias de hoje, a Teoria do Capital Humano e o empreendedorismo tornaram-se valores sociais. Vivemos em um tempo de empresariamento da sociedade, ou seja, conforme discutimos, trata-se de "[...] fazer do mercado, da concorrência e, por conseguinte, da empresa o que poderíamos chamar de poder enformador da sociedade" (FOUCAULT, 2008, p. 203);

- O novo papel do Estado - funçôes compensatórias - insere-se no contexto das novas relaçóes Estado e economia, da impermeabilidade do imposto econômico e do imposto social, e dos decorrentes processos de descentralização da educação. Tal descentralização implica mais comunidade e menos sociedade;

- A nova organização do trabalho, que envolve descentralização, delegação de responsabilidades e investimento em capital humano, está diretamente relacionada com as novas circunstâncias da economia mundial, cujas palavras de ordem são flexibilidade e dinamicidade.

\section{O movimento Todos Pela Educação e a política educacional brasileira neste início de século}

A pesquisa que apresentamos nesta seção teve como objetivo analisar o movimento Todos Pela Educação (TPE), buscando compreender suas condiçóes de proveniência e emergência, bem como seus efeitos no cenário educacional brasileiro na atualidade. Assim, ela se dividiu em duas fases distintas, mas relacionadas. Nos limites deste texto, serão apresentadas mais detidamente as análises que dizem respeito à genealogia do Movimento, anunciando seus efeitos no cenário educacional brasileiro, em especial, a instituição da performatividade enquanto produtividade como um valor fundamental na política educacional brasileira na atualidade. 
Os materiais de pesquisa consistiram em oito publicaçóes do Movimento, entre manuais de divulgação de suas açóes e relatórios de monitoramento das metas (TODOS PELA EDUCAÇÃO 2008a, 2008b, 2009a, 2009b, 2010, 2011a, 2011b, 2012).

Partindo da análise desses materiais, um primeiro movimento metodológico realizado foi o de proceder a um recuo histórico para mostrar as condiçóes de proveniência de movimentos como o Todos Pela Educaçáo. Foi necessário, então, visibilizar as tramas discursivas que constroem a grande verdade da educaçáo para todos. Essa "verdade da escola", alinhada aos discursos que instituem a necessidade da reforma educacional, dão as condiçôes para a instituição desses tipos de movimentos. Assim, a pesquisa procura mostrar de que forma, a partir de que condiçóes e disputas, institui-se e naturaliza-se a escola estatal como uma grande verdade, como uma instituição cuja existência é praticamente inquestionável na atualidade. Essa naturalizaçáo, essa unanimidade da escola estatal que deve ser "para todos" se estabelece em uma relação íntima com o processo de governamentalização do Estado e articula-se ao contexto de uma proliferação discursiva acerca da importância da reforma educacional.

No contexto brasileiro, em um primeiro momento, temos um discurso da reforma da educação que se constitui em um contexto em que o Estado deve prover educação para todos, como vimos já nas discussóes da Escola Nova, bem como nos projetos de reforma educacional propostos no período pós-guerra (alicerçados nas agendas educacionais propostas pelos organismos internacionais), em que se entendia que prover acesso à educaçáo, buscando desenvolver o Capital Humano, seria uma importante via para o desenvolvimento das naçóes.

Em um segundo momento, temos uma ênfase em projetos de reforma educacional que devem se dar em um Estado que redefine o seu papel, descentraliza funçôes e passa a imprimir uma postura gerencialista às suas ações, transferindo responsabilidades para a sociedade civil. Passamos a um discurso de reforma educacional que tem como palavra-chave a "qualidade", mas uma qualidade "quantitativa", que pode ser traduzida em números. Essas podem ser entendidas como as condições de proveniência de movimentos como o TPE.

Por sua vez, a emergência do movimento Todos Pela Educação se dá em um cenário em que, imersos numa racionalidade política neoliberal, considerando-se suas implicaçóes, os idealizadores do movimento destacam três fatores fundamentais: a necessidade de um sistema educacional capaz de conduzir o país rumo ao desenvolvimento, a constatação de uma crise política que demandava uma mobilização social em prol da construção de valores que somente poderiam se concretizar através da 
educação e a constatação da incompetência dos responsáveis pela gestão da educação no país.

Sáo vários os documentos em que essa história é contada, repetidas vezes, e, a cada vez, com um detalhamento maior e colocando luz sobre questóes diferentes. Um dos documentos mais complexos, nesse sentido, é uma publicação de 2011, intitulada Todos Pela Educação: 5 anos, 5 metas, 5 bandeiras, no qual se percebe um maior detalhamento da trajetória de cinco anos do movimento, evidenciando algumas parcerias que não haviam sido explicitadas anteriormente (TODOS PELA EDUCAÇÃ̂, 2011a). Nesse material, são descritas as alianças iniciais através das quais o movimento começou a ser gestado, começou a ganhar forma.

A primeira questáo que aparece elencada como um dos acontecimentos que levaram à organização do movimento Todos Pela Educação está relacionada à compreensão de que a educação é a principal responsável pelo desenvolvimento de um país. Sem educação formal, sem desenvolvimento do capital humano dos sujeitos, não há como o país avançar em termos de desenvolvimento. Entende-se que é necessário que a educação conduza o país rumo a seus objetivos, sejam eles econômicos, sociais, políticos. E essa constatação se relaciona diretamente à segunda questáo mobilizadora da criação do TPE: o entendimento da existência de uma "crise política", em que se acredita que haja a necessidade de mobilização social, e, mais uma vez, para uma possível solução, a via seria a educação. Complementando os motivos que levaram à criaçáo do movimento, estaria a incompetência dos profissionais responsáveis pela gestão da escola, que demonstravam "falta de preparo técnico" na opinião dos fundadores do TPE. Portanto, esse tripé é apontado pelo movimento Todos Pela Educação como o motivador da mobilização em prol da sua criação.

A partir daí, organizou-se uma espécie de "agenda das prioridades da educação no Brasil” (TODOS PELA EDUCAÇÃO, 2011a, p. 19), que, em pouco tempo, resultou na elaboração do documento " 10 causas e 26 compromissos". Divulgado em julho de 2005, configurou-se não só como o primeiro documento público do movimento, mas também como o documento a partir do qual as metas, as bandeiras e as alianças do TPE seriam organizadas posteriormente. Pode-se dizer que esse é o documento que materializa, de certa forma, a emergência do movimento.

É interessante também observar toda a simbologia referida pelo movimento ao adotar como data-limite para o alcance das metas o ano de 2022, fazendo referência ao bicentenário da independência do Brasil. Em uma perspectiva desenvolvimentista, aliada a um apelo nacionalista, o ano 2022 é apresentado como um marco para a possibilidade de que o Brasil tenha uma independência de fato, e não somente de direito. $\mathrm{O}$ que possibilitaria essa independência de fato seria uma posição invejável nos rankings internacionais de educação. 
Ainda antes do lançamento oficial, foram definidas as três áreas fundamentais de atuação do TPE: a área técnica, a área de articulação e relaçôes institucionais e a área de comunicação. Coube à área técnica a definição das cinco metas do movimento. Para isso, foi organizado, "em abril de 2006, um workshop de dois dias, em Guarulhos (SP)" (TODOS PELA EDUCAÇÃO, 2011a, p. 22), a partir do qual a equipe escolhida para compor a área técnica realizou a tarefa.

A partir daí, o que se segue, em especial durante o ano de 2007, é um trabalho bastante atuante na divulgação do movimento na mídia. O TPE não é um movimento de atuação direta junto às escolas, mas um movimento que busca mobilizar a sociedade, modificar a cultura da relação das famílias com a escola de seus filhos e influenciar políticas públicas na área da educação. Essas são as principais estratégias de atuação do TPE.

Assim, desde o seu lançamento oficial até o momento, tem-se investido fortemente em campanhas publicitárias - embora esse investimento tenha sido mais intenso nos cinco primeiros anos do TPE - em rádio, televisão e mídia impressa. Além disso, a principal estratégia de atuação do movimento é a sua articulação com as três esferas governamentais - municipal, estadual e federal, influenciando fortemente a implementação de políticas educacionais no Brasil neste início de século. Essa influência se dá no sentido de um esforço do TPE para imprimir à educaçáo brasileira a já citada e constantemente referenciada pelo movimento "cultura de metas" (TODOS PELA EDUCAÇÃO, 2009a, p. 41). Assim, percebe-se como um de seus principais efeitos no cenário educacional brasileiro na atualidade a centralidade da performatividade, no sentido que lhe atribui o pesquisador Stephen Ball (2002, p. 4):

A performatividade é uma tecnologia, uma cultura e um modo de regulação que se serve de críticas, comparaçôes e exposiçôes como meios de controlo, atrito e mudança. Os desempenhos (de sujeitos individuais ou organizaçóes) servem como medidas de produtividade e rendimento, ou mostras de 'qualidade' ou ainda 'momentos' de promoção ou inspeção. Significam, englobam e representam a validade, a qualidade ou valor de um indivíduo ou organização dentro de um determinado âmbito de julgamento/avaliação.

Em um retorno constante aos materiais de pesquisa, é possível perceber o quanto a instituição de uma lógica da performatividade, principal efeito do movimento Todos Pela Educação, tem pautado a instituição de políticas educacionais no Brasil neste início de século. 


\section{A proliferação das políticas de assistência social no Brasil: compreendendo suas condições históricas}

Necessitamos de uma consciência histórica da situação presente. (FOUCAULT, 2002b, p. 232).

As palavras de Michel Foucault (2002b), escolhidas para abrir esta seção, apresentam uma profunda relação com a terceira investigação que apresentaremos neste artigo. Tal pesquisa teve como propósito compreender como as Políticas de Assistência Social, utilizando a educação escolarizada como lócus privilegiado de efetivação, operam sobre a população na atualidade e que implicações tais políticas vêm produzindo na escola contemporânea. É possível perceber que se tratou de uma investigação a qual privilegiou uma forma de fazer pesquisa que está ancorada no presente, nas problemáticas, nas tensóes e nos desafios que se desenvolvem na atualidade. No entanto, essa pergunta pelo presente leva imediatamente para o passado, buscando compreender as formas de sua constituição: "Como [Foucault] mesmo diz, sua relação com a história é estabelecida a partir de um problema que se coloca no presente e, para a resolução, necessita-se voltar ao passado" (RAGO, 2002, p. 263). Dessa forma, a referida investigação começa pelo presente, analisando as formas de atuação que a Assistência Social, em articulação com a Educação, vem produzindo sobre os sujeitos e a população na atualidade, para posteriormente lançar um olhar para a história de constituição de tais políticas.

Com o objetivo de responder a pergunta pelo presente, selecionou-se um conjunto de documentos oficiais que materializam e regulamentam as Políticas de Assistência Social na atualidade, são eles: Constituição Federal de 1988 (BRASIL. 1988), Lei Orgânica de Assistência Social (LOAS) (BRASIL, 1993a), Política Nacional de Assistência Social (PNAS) (BRASIL, 2004), Norma Operacional Básica (NOB/SUAS) (BRASIL, 2005) e o Plano Brasil Sem Miséria (BRASIL, 2011).

Em contato com esses cinco primeiros documentos, foi possível perceber que eles forneciam informaçóes importantes sobre o funcionamento das Políticas de Assistência Social na atualidade. Além disso, traziam algumas informaçóes históricas sobre a constituição dessas políticas no território nacional, que remetiam a períodos históricos anteriores à regulamentação das Políticas de Assistência Social no Brasil. Esse fato se tornou fundamental no fazer investigativo, pois mostrou que, para identificar e descrever a proveniência e as condiçōes de emergência dessas políticas, era necessário olhar práticas, discursos e saberes que se configuraram em um período anterior a sua construção. Foi nesse momento que incluiu-se, também, como material de análise, alguns pronunciamentos presidenciais retirados do site da Biblioteca da Presidência da 
República de épocas distintas e discursos materializados em veículos midiáticos como revistas e jornais, disponíveis nos acervos digitais da Folha de Sáo Paulo (Folha da Manhã e Folha da Noite) e no acervo digital da Revista Veja, da década de 1950 em diante. Esses materiais foram fundamentais e funcionaram como superfície de emergência permitindo visualizar as práticas desenvolvidas no âmbito da Assistência Social e da Educação em épocas históricas diferentes.

Assim, analisando o funcionamento de tais políticas na atualidade, primeiro exercício desenvolvido na pesquisa, argumenta-se que, com a emergência do neoliberalismo brasileiro e a correlata constituição da inclusão como imperativo de Estado, podemos assistir à proliferação das Políticas de Assistência Social no Brasil, a qual ocorre em articulação com um fenômeno que pode ser denominado educacionalização do social ou uma obsessão contemporânea pela educação: "Este conceito deve ser identificado com a expansão quantitativa bem como qualitativa da intervenção educativa na sociedade" (SMEYERS; DEPAEPE, 2008, p. 3). Ou seja, percebe-se uma convocação incessante que é realizada ao Campo da Educação como instância de solução de uma variedade de problemas sociais relacionados à saúde, ao desemprego, à produtividade, à natalidade, à reproduçáo etc. De forma correlata, a educaçáo escolarizada passa a ser utilizada como lócus privilegiado de efetivaçáo de uma variedade de políticas, programas e projetos assistenciais, o que acaba produzindo uma redefinição das funçôes da escola pública, alargando consideravelmente suas funçôes. Nóvoa (2009) denomina esse processo de transbordamento da escola, o qual estaria associado à imagem dessa instituiçáo como regeneradora, salvadora e reparadora da sociedade. Ele diz que:

A escola no centro da colectividade remete para uma instituição fortemente empenhada em causas sociais, assumindo um papel de 'reparadora' da sociedade; remete para uma escola de acolhimento dos alunos e, até, de apoio comunitário às famílias e aos grupos mais desfavorecidos; remete para uma escola transbordante, uma escola utópica que procura compensar as 'deficiências da sociedade', chamando a si todas as missóes possíveis e imagináveis. (NÓVOA, 2009, p. 60, grifo do autor).

Segundo o autor, a escola foi se desenvolvendo por acumulação de missóes e de conteúdos que a levou a assumir uma infinidade de tarefas. Isso nos mostra que esse processo não nasce na Contemporaneidade, mas está presente ao longo da história da Educação. Dessa forma, olhar para traços específicos dessa história constituiu o exercício desenvolvido na segunda parte da pesquisa, na qual se buscou compreender a proveniência e as condiçôes de emergência das Políticas de Assistência Social no Brasil. 
Inicialmente ${ }^{2}$, tentando destacar um primeiro fio de proveniência, foram descritas práticas de assistência social vinculadas à caridade e a uma verdade religiosa que pretende, a partir de princípios transcendentais e divinos, governar a vida dos homens aqui na Terra. É por meio da crença na salvação eterna que se torna possível exercer o poder sobre as condutas dos homens, determinando a forma como devem agir nesse mundo. Foucault (2010, p. 58) lembra-nos de que "[...] [quanto] mais os homens estâo preocupados com a sua salvação no além, mais é fácil aqui embaixo governá-los".

Uma questão importante e ser destacada é que, já nessa época, percebe-se uma associação/articulação entre práticas assistenciais e práticas educativas. Nessa primeira associação, é a educação que passa a ser introduzida no interior do espaço assistencial. Podemos visualizar práticas educativas funcionando no interior das Santas Casas de Misericórdia, por exemplo. Atualmente, observamos um movimento contrário, é a assistência social que entra na escola e passa a funcionar por meio de programas e projetos variados, e não o contrário. Ao fim e ao cabo, o que é preciso ressaltar se refere ao fato de que, já nessa época, assistência e educação mantinham algum tipo de entrelaçamento.

A segunda forma de proveniência pode ser encontrada entre meados do século XIX e início do século XX, mais especificamente, no decorrer da Primeira República do Brasil (1889-1930). Nessa época, visualizamos um movimento de racionalização das práticas de governo que modifica as práticas de assistência social, fazendo-as alicerçar-se em princípios mais racionais e biológicos: emergem, portanto, os movimentos higienistas e sanitaristas que se proliferam amplamente pelo Brasil nesse período. Aqui, a preocupação direciona-se para a vida biológica da população e seus efeitos coletivos, não tanto à salvaçấo das almas, como anteriormente. Com essa racionalização das práticas de governo, vemos iniciar, no Brasil, um processo de governamentalizaçáo do Estado, que ocorre a partir do momento em que a população passa a ser objeto e objetivo de governo: cálculos estatísticos começam a ser produzidos, e a família é utilizada como instrumento de governo. No quadro das artes liberais de governar, podese assistir à emergência de estratégias biopolíticas que agem sobre a vida da população, tentando prevenir o alastramento de doenças e de outros males. Essas práticas começam a utilizar a escola para entrar em funcionamento. Nesse momento, são as práticas assistenciais que entram no espaço educacional e veem na educação uma forma de agir sobre o corpo infantil, estabelecendo regras de contato, moldando comportamentos, ensinando higiene etc. Parece que podemos visualizar aqui uma primeira porta de entrada da assistência social na instituição escolar, o que nos permite visualizar, já aqui, uma espécie de alargamento das funções da escola. 
Todo esse movimento ocorrido nesse período dá as condiçôes para que as políticas de assistência social possam emergir no Brasil, na década de 1930, momento em que o Estado passa a reconhecer suas responsabilidades sociais e cria determinados órgãos e serviços para atender, mesmo que minimamente, a essas demandas. Essa emergência acontece vinculada a uma verdade nacionalista que passa a pautar fortemente os currículos escolares. Esse movimento se dá no interior de um Estado forte pautado pela ditadura do Estado Novo.

Assim, o estudo permite argumentar que: se a Ditadura do Estado Novo deu as condiçóes para a emergência das políticas de assistência social no Brasil, o surgimento da racionalidade neoliberal brasileira e a correlata constituição da inclusão como imperativo de Estado possibilitaram não a emergência, mas a proliferação das Políticas de Assistência Social. Tal proliferação aparece associada a uma nova estratégia que surge no Brasil a partir de meados da década de 1990. Trata-se dos Programas de Renda Condicionada, tais como Bolsa-Escola, atualmente chamado Bolsa-Família.

Essa transferência de renda mínima funciona com o objetivo de evitar que esses sujeitos sejam excluídos da dinâmica competitiva, constituindo-se numa ameaça ao funcionamento do jogo neoliberal. Lembremos que uma das regras gerais da racionalidade política neoliberal é a regra da não exclusão. Assegurar a participação de todos. Garantir o acesso de todos. Não permitir que ninguém seja excluído ou se mantenha fora do jogo. Foucault (2008, p. 277-278, grifo nosso) destaca que "[...] a sociedade inteira deve ser permeada por esse jogo econômico [...] cabe à regra do jogo imposta pelo Estado fazer que ninguém seja excluido desse jogo". Eis uma das tarefas atribuídas às Políticas de Assistência Social, sobretudo, quando elas se articulam com a Educação.

Compreender as Políticas de Assistência Social como estratégias inclusivas que mantém os sujeitos como participantes do jogo do mercado neoliberal, não significa afirmar sua negatividade ou posicionar-se contra determinados programas sociais. Sabemos dos benefícios que tais programas têm produzido na vida das populaçôes que vivem em condiçóes de extrema pobreza. Porém, também não podemos lançar um olhar inocente acreditando que elas vieram para o bem da humanidade. Para muito além do bem e do mal, tais políticas e programas produzem efeitos na vida das pessoas e ao garantir algumas possibilidades mínimas de consumo e de participação no jogo econômico, também se está incluindo tais sujeitos nas tramas de uma racionalidade política neoliberal que se instalou fortemente no Brasil, pelo menos, desde a década de 1990. 


\section{Conclusão}

Entendemos, assim, que, a partir da visibilização dos movimentos metodológicos empreendidos e dos achados apresentados em cada uma das pesquisas, é possível perceber a importância dos estudos genealógicos na análise de políticas educacionais. Eles podem permitir que se construa um panorama dos processos de constituição tanto das políticas quanto das respectivas práticas por e com elas instituídas. Por meio da proliferaçáo de acontecimentos que tornam visíveis e das múltiplas conexóes que trazem à tona, os estudos genealógicos de políticas educacionais têm se tornado instrumentos importantes para a compreensão do cenário educacional contemporâneo. Compreender como as coisas se constituíram historicamente nos parece importante para olhar de outra forma para o presente, problematizando práticas que muitas vezes apresentam-se naturalizadas em nossos dias. Isso nos permite não só olhar para o campo da educaçáo ou para a escola de outro jeito, mas também agir de outros modos acreditando que podemos inventar outras e novas formas de fazer educação.

É possível também perceber o quanto uma pesquisa genealógica se constrói de forma muito particular, a partir do objeto de estudo em questáo e de um caminho que se constitui nos rastros dos documentos, dos materiais, sujeitos com os quais o pesquisador se depara no decorrer do estudo, sem que se possa definir um método único a ser aplicado em diferentes investigaçôes. Porém, para além das particularidades de cada uma das pesquisas apresentadas, entendemos que a genealogia foucaultiana nos permite analisar os processos de instituição de práticas muitas vezes naturalizadas nos discursos educacionais. Compreender seus processos de constituição, bem como as lutas engendradas nesses processos pode nos ajudar a problematizar sua produtividade e questionar seus efeitos no contexto educacional. Conforme explicitado na primeira seção do artigo, pode-se dizer que este é um dos principais desafios de uma pesquisa genealógica, ou seja, compreender como as coisas chegaram a ser como são a partir da trama histórica nas quais estão enredadas.

\section{Notas}

1 A ANPAE foi fundada em 1961 sob a denominação "Associação Nacional de Professores de Administração Escolar, passou a se chamar Associação Nacional de Profissionais de Administração Escolar em 1971. Em 1980, seu nome foi alterado para Associação Nacional de Profissionais de Administração da Educação, assumindo depois, em 1996, a denominação que permanece até hoje: Associação Nacional de Política e Administração da Educação, mantendo a sigla ANPAE durante toda a sua existência” (CATANI; GILIOLI, 2004, p. 105). 
${ }^{2}$ Para destacar esse primeiro fio de proveniência, destacamos um longo período histórico que vai desde o século XII até meados do século XIX. Nesse período podemos visualizar a existência das Santas Casas de Misericórdia e das Rodas dos Expostos que existiam no Brasil desde o primeiro século da colonização portuguesa.

\section{REFERÊNCIAS}

ALBUQUERQUE JÚNIOR, Durval Muniz de. A história em jogo: a atuação de Michel Foucault no campo da historiografia. Anos 90, Porto Alegre, v. 11, n. 20, p. 79-100, jan./dez. 2004.

BALL, Stephen J. Reformar escolas, reformar professores e os terrores da performatividade. Revista Portuguesa de Educação, Braga, ano 15, n. 2, p. 3-23, 2002.

BRASIL. Constituição da República Federativa do Brasil. Brasília, DF, 5 out. 1988. Disponível em:

<http://www.planalto.gov.br/ccivil_03/Constituicao/Constituicao.htm> Acesso em: 20 jun. 2011.

BRASIL. Lei no 8742, de 7 de dezembro de 1993. Dispóe sobre a organização da Assistência Social e dá outras providências. Diário Oficial da União, Brasília, DF, 8 dez. 1993a. Disponível em: <http://www.planalto.gov.br/ccivil_03/leis/18742.htm $\geq$. Acesso em: 12 jul. 2012.

BRASIL. Plano decenal de educação para todos. Brasília, DF: MEC, $1993 \mathrm{~b}$.

BRASIL. Ministério do Desenvolvimento Social e Combate à Fome. Secretaria Nacional de Assistência Social. Politica Nacional de Assistência Social. Brasília, DF: MDS/SNAS, 2004. Disponível em:

<http:/www.mds.gov.br/gestaodainformacao/monitoramento/monitoramento-dosuas/arquivos/politica-nacional-de-assistencia-social-pnas.pdf/view $\geq$. Acesso em: 20 abr. 2011.

BRASIL. Ministério do Desenvolvimento Social e Combate à Fome. Secretaria Nacional de Assistência Social. Norma Operacional Básica NOB/SUAS: construindo as bases para a implantação do Sistema Único de Assistência Social. Brasília, DF: MDS/SNAS, 2005. Disponível em:

<http://www.mds.gov.br/assistenciasocial/resolveuid/23ad2e16c4d257cdb672c8bb3 $52731 \mathrm{fa} /$ download $>$. Acesso em: 25 jul. 2011. 
BRASIL. Ministério do Desenvolvimento Social e Combate à Fome. Plano Brasil Sem Miséria. Brasília, DF: MDS/SNAS, 2011. Disponível em:

<http://www.brasilsemmiseria.gov.br/documentos>. Acesso em: 20 set. 2011.

BREJON, Moysés. Alguns aspectos da formação de administradores escolares. Salvador: ANPAE, 1966. (Caderno de Administração Escolar, n. 3).

CATANI, Afrânio Mendes; GILIOLI, Renato de Sousa Porto. Administração Escolar: a trajetória da ANPAE na década de 1960. Rio de Janeiro: DP\&A, 2004.

DIAS, José Augusto. Sistema escolar brasileiro. Niterói, RJ: ANPAE, 1972. (Caderno de Administração Escolar n. 5).

ESCOBAR, Arturo. La invención del Tercer Mundo: construcción y desconstrucción del desarollo. Colombia: Norma, 2007. v. 1.

FOUCAULT, Michel. Vigiar e punir: nascimento da prisão. Tradução por Raquel Ramalhete. Petrópolis: Vozes, 1987.

FOUCAULT, Michel. Nietzsche, a genealogia e a história. In: FOUCAULT, Michel. Microfísica do Poder. 17. ed. Rio de Janeiro: Graal, 2002a. p. 15-37. v. 1.

FOUCAULT, Michel. A arqueologia do saber. 6. ed. Rio de Janeiro: Forense Universitária, 2002b. v. 1.

FOUCAULT, Michel. Precisóes sobre o poder: respostas a certas críticas. In: FOUCAULT, Michel. Estratégia, Poder-Saber. 2. ed. Rio de Janeiro: Forense Universitária, 2006. (Ditos \& Escritos, n. 4). p. 270-280.

FOUCAULT, Michel. Nascimento da Biopolítica: curso no Collège de France (19781979). São Paulo: Martins Fontes, 2008. v. 1.

FOUCAULT, Michel. Do governo dos vivos: curso no Collège de France: 19791980: excertos. Rio de Janeiro: Achiamé, 2010. v. 1.

HARVEY, David. Condiçâo pós-moderna. São Paulo: Edições Loyola, 2001.

MARTON, Scarlett. Nietzsche: uma filosofia a marteladas. 5. ed. São Paulo: Brasiliense, 1999.

MASCARO, Carlos Corrêa. A administração escolar na América Latina. Salvador, BA: ANPAE, 1968. (Caderno de Administração Escolar, n. 4).

MELCHIOR, José Carlos de Araújo. Financiamento da Educação no Brasil: recursos financeiros públicos e privados. São Paulo: ANPAE, 1972. (Caderno de Administração Escolar, n. 4). 
MOREY, Miguel. La cuestión del método. In: FOUCAULT, Michel. Tecnologías del yo y otros textos afines. Barcelona: Paidós Ibérica, 1991. p. 9-44. v. 1.

NIETZSCHE, Friedrich Wilhelm. Obras Incompletas. 6. ed. São Paulo: Nova Cultural, 1996. v. 1.

NIETZSCHE, Friedrich Wilhelm. Humano Demasiado Humano. São Paulo: Companhia das Letras, 2000.

NIETZSCHE, Friedrich Wilhelm. A Gaia Ciência. São Paulo: companhia das Letras, 2001.

NIETZSCHE, Friedrich Wilhelm. A genealogia da moral. 5. ed. São Paulo:

Centauro, 2004. v. 1.

NÓVOA. Antônio. Professores: imagens do futuro presente. Lisboa: Educa, 2009. v. 1.

RIBEIRO, José Querino. Introdução à administração escolar. Salvador: ANPAE, 1965. (Caderno de Administração Escolar, n. 2).

RAGO, Margareth. Libertar a história. In: RAGO, Margareth; ORLANDI, Luiz B. Lacerda; VEIGA-NETO, Alfredo (Org.). Imagens de Foucault e Deleuze: ressonâncias nietzschianas. Rio de Janeiro: DP\&A, 2002. p. 13-34. v. 1.

SANDER, Benno. Administração da Educação no Brasil: evolução do conhecimento. Fortaleza: Edições UFC, 1982. (Caderno de Administração Escolar, n. 7).

SMEYERS, Paul; DEPAEPE, Marc. Educational Research: the educationalization of social problems. Berlin: Springer Science+Business, 2008. v. 3 .

TEIXEIRA, Anísio S. Natureza e função da administração escolar. Salvador: ANPAE, 1964. (Caderno de Administração Escolar, n. 1).

TEIXEIRA, Anísio S. et al. Administração Escolar. Salvador: ANPAE, 1968.

TODOS PELA EDUCAÇÃO. Todos Pela Educação: relatório de Atividades 2008. São Paulo: Todos Pela Educaçáo, 2008a.

TODOS PELA EDUCAÇÃO. De Olho nas Metas: primeiro relatório de acompanhamento das 5 Metas do movimento Todos Pela Educação. São Paulo: Todos Pela Educação, 2008b.

TODOS PELA EDUCAÇÃO. Todos Pela Educação 2006-2009. São Paulo: Todos Pela Educaçáo, 2009a. 
TODOS PELA EDUCAÇÃO. De Olho nas Metas 2009: segundo relatório de acompanhamento das Metas do movimento Todos Pela Educação São Paulo: Todos Pela Educação, 2009b.

TODOS PELA EDUCAÇÃO. De Olho nas Metas 2010: terceiro relatório de acompanhamento das Metas do movimento Todos Pela Educação. São Paulo: Todos Pela Educação, 2010.

TODOS PELA EDUCAÇÃO. Todos Pela Educação: 5 anos, 5 metas, 5 bandeiras. São Paulo: Todos Pela Educação, 2011a.

TODOS PELA EDUCAÇÃO. De Olho nas Metas 2011: quarto relatório de monitoramento das 5 Metas do Todos Pela Educação. São Paulo: Todos Pela Educação, 2011b.

TODOS PELA EDUCAÇÃO. Anuário da Educação Brasileira 2012. São Paulo: Todos Pela Educação/Editora Moderna, 2012.

VEIGA-NETO, Alfredo. Michel Foucault e Educação: há algo de novo sob o sol? In: VEIGA-NETO, Alfredo (Org.). Crítica Pós-Estruturalista e Educação. Porto Alegre: Sulina, 1995. p. 9-56.

VEIGA-NETO, Alfredo. Foucault \& a Educação. Belo Horizonte: Autêntica, 2003. v. 4.

VEIGA-NETO, Alfredo. Na oficina de Foucault. In: KOHAN, Walter Omar; GONDRA, José (Org.). Foucault 80 anos. Belo Horizonte: Autêntica, 2006. p. 7991.

VEIGA-NETO, Alfredo. Teoria e método em Michel Foucault (im)possibilidades. Cadernos de Educação, Pelotas, RS, n. 34, p. 83-94, set./dez. 2009.

VEIGA-NETO, Alfredo; LOPES, Maura Corcini. Há teoria e método em Michel Foucault? Implicaçóes educacionais. In: CLARETO, Sônia Maria; FERRARI, Anderson (Org.). Foucault, Deleuze \& Educação. Juiz de Fora, RJ: Editora da UFJF, 2010. p.33-47.

VEYNE, Paul. Como se escreve a história: Foucault revoluciona a história. 4. ed. Brasília: Editora da UNB, 1998. 


\section{Foucault's genealogy and edu- cation policies: analytical pos- sibilities}

\begin{abstract}
This paper addresses the importance of Foucault's genealogy to the analysis of education policies. The paper has been divided into four sections. In the first section, the authors argue that Foucault's genealogy, under strong Nietzsche's inspiration, is a kind of analysis that opposes the idea of history as a search for "origin" (Ursprung), as it seeks to understand the study objects by considering their historical plot, in an attempt to denaturalize all that is seen as if it had always been there in the world. By problematizing, describing and analyzing what is said about education policies, the genealogy enables us to evidence the processes of constitution of such policies. In the second, third and fourth sections, the authors present three researches in which Foucault's genealogy was employed as an analytical tool. The first research focuses on the Education policies, the emergence of education administration and its displacement to education management. The second research presents the conditions for provenience and emergence of the movement known as Everyone for Education and points out the institution of performativity as one of their major effects on the Brazilian education scenario nowadays. The third research analyzes both the way that Social Assistance Policies have operated on the population through the use of school education as a privileged locus and the implications of such policies in the contemporary school, and it also takes a genealogical look to the constitution of those policies at present.
\end{abstract}

Keywords: Public Policies in Education. Foucault, Michel. History.

\section{Genealogía foucaultiana y políticas educacionales: posi- bilidades analíticas}

\section{Resumen}

En este artículo aborda la importancia de la genealogía foucaultiana en el análisis de políticas educacionales. El trabajo fue dividido en cuatro secciones. En la primera sección, se argumenta que la genealogía foucaultiana, de fuerte inspiración "nietzscheana", es una forma de análisis que se opone a la historia como búsqueda del "origen" (Ursprung), pues procura comprender los objetos de estudio a partir de su trama histórica, indagando desnaturalizar todo aquello que pasa a ser visto como si estuviera desde siempre allí, en el mundo. Al problematizar, describir y analizar los discursos sobre políticas educacionales, la genealogía posibilita visibilizar los procesos de constitución de esas políticas. En la segunda, tercera y cuarta sección, las autoras presentan tres investigaciones en las cuales la genealogía foucaultiana se constituyó como herramienta analítica. La primera investigación presentada tiene como foco central Las políticas educacionales, la emergencia de la administración de la educación y su desplazamiento para la administración educacional. La segunda investigación presenta las condiciones de procedencia y emergencia del movimiento Todos Por la Educación y anuncia la institución de la performatividad como uno de sus principales efectos en el escenario educacional brasilero en la actualidad. La tercera investigación, al analizar como las Políticas de Asistencia Social - utilizando la educación escolar como lugar privilegiado de eficacia - operan sobre la población en la actualidad y que implicaciones estas políticas vienen produciendo en la escuela contemporánea y lanza una visión genealógica para la forma de constitución de tales políticas en el presente.

Palabras claves: Políticas Públicas en Educación. Foucault, Michel. Historia. 


\section{Viviane Klaus}

E-mail:viviklaus@unisinos.br

\section{Morgana Domênica Hattge}

E-mail:mdhattge@univates.br

\section{Kamila Lockmann}

E-mail: kamila.furg@gmail.com

Recebido em: 26/09/2014 Aprovado em: 15/12/2014 
